\title{
Analisis Nilai Kepadatan Tanah Quarry Ia, Samba, Nanganesa Dan Wokonio
}

\author{
Arnoldus Wilhelmus Rudu ${ }^{1}, * V^{*}$ eronika Miana Radja ${ }^{2}$, Yohanes Laka Suku ${ }^{3}$ \\ ${ }^{1,2,3}$ Program Studi Teknik Sipil, Fakultas Teknik, Univesitas Flores, Ende NTT \\ *) Correspondence e-mail: veronika_mira@yahoo.com
}

\begin{abstract}
ABSTRAK
Tanah merupakan bagian yang utama dalam sistim konstruksi.dalam hal ini kaitannya dengan pemadatan, tidak semua jenis tanah dapat digunakan untuk bahan pemadatan. Bahan yang digunakan dalam pengujian ini adalah pasir Ia, Samba, Nanganesa dan Wokonio yang berada dalam kabupaten Ende, yang di uji di Laboratorium Mekanika tanah Fakultas Teknik Universitas Flores. Dalam penelitian ini di lakukan pencampuran secara random yakni sebanyak 25\%, 50\%, dan 75\% untuk mendapatkan nilai kepadatan maksimal. Pengujian sifat meaknis campuran tanha menggunakan metode standar proctor.Hasil pengujian ini menunjukan bahwa dari penggabungan tanah tersebut dapat memberi perubahan pada nilai kepadatan volume tanah kering $\left(\gamma_{\text {dmax }}\right)$ dan kadar air $\left(\omega_{\text {copt }}\right)$ maksimal. Nilai kepadatan tanah dari masing-masing quary antara lain: quary Ia $\gamma_{d}$ sebesar 1,78 kg/cm ${ }^{3}, q u a r y$ Samba $\gamma_{d}$ sebesar $1,74 \mathrm{~kg} / \mathrm{cm}^{3}$, quary Nanganesa $\gamma_{d}$ sebesar $1,67 \mathrm{~kg} / \mathrm{cm}^{3}$ dan quary Wokonio $\gamma_{d}$ sebesar 1,355 $\mathrm{kg} / \mathrm{cm}^{3}$. Nilai kepadatan tanah untuk komposisi campuran tanah di peroleh $\gamma_{d}$ sebesar $1,85 \mathrm{~kg} / \mathrm{cm}^{3}$, dengan komposisi campuran dari quary Ia 75 \% dan Nanganesa $25 \%$ serta quary Ia 75 \% dan Samba $25 \%$. Berdasarkan hasil pengujian yang dilakukan, maka hasil pemadatan yang baik adalah dengan menggunakan campuran pasir Ia dan Samba atau pasir Ia dan Nanganesa.
\end{abstract}

Kata kunci: Pemadatan Tanah, Sifat tanah, Quarry tanah

\section{PENDAHULUAN}

Tanah lanau merupakan tanah yang berbutir sedang, tidak berkohesi, kurang plastis, dan kerapatan relatif rendah sehingga sulit dipadatkan, karena tanah tersebut memiliki sifat yang berbeda maka dalam usaha perbaikan tanah atau pemadatan untuk timbunan perlu adanya perbandingan komposisi tanah yang tepat agar dapat menghasilkan pemadatan maksimal.

Tanah merupakan salah satu bahan konstruksi yang harus diperhatikan peranannya. Timbunan jalan raya menggunakan tanah yang ekonomis sebagai bahan konstruksi walau demikian sama halnya dengan konstruksi lainnya, tanah harus dipakai setelah melalui proses pengendalian mutu. Salah satunya adalah dengan melakukan proses perbaikan tanah dengan cara pemadatan, agar diperoleh tanah yang stabil dan mempunyai kekuatan tanah dasar yang baik.

Uji pemadatan sangat bergantung kepada jenis tanah, kadar air, dan usaha yang diberikan. Apabila tanah dipadatkan secara sembarangan, hasilnya tidak mencapai kepadatan maksimum. Di Kabupaten Ende tanah yang sering digunakan dalam pekerjaan pemadatan biasa diambil dari quari Ia, Samba, Nanganesa, dan Wokonio. Dalam proses pengujian awal di laboratorium tanah dari ke empat quari tersebut tidak memenuhi syarat ketentuan. Oleh karena itu berdasarkan uraian diatas, maka perlu adanya penelitian tentang "Analisis Perbandingan Komposisi Tanah Quari Ia, Samba, Nanganesa dan Wokonio Terhadap Pemadatan Tanah". Tujuan yang ingin dicapai dari penelitian ini adalah, mengetahui perbandingan kompoisi tanah yang baik untuk pemadatan maksimal sesuai standar.

\section{Defenisi Tanah}

Menurut Braja M. Das (1988) tanah didefinisikan sebagai material yang terdiri dari agregat (butiran) mineral-mineral padat yang tidak tersementasi (terikat secara kimia) satu sama lain dan dari bahan-bahan organik yang telah melapuk (yang berpartikel padat) disertai dengan zat cair dan gas yang mengisi ruangruang kosong di antara partikel-partikel padat tersebut. Menurut Hardiyatmo (2002) mendefinisikan 
tanah dalam pandangan Teknik Sipil adalah himpunan mineral, bahan organik dan endapan-endapan yang relatif lepas (loose) yang terletak diatas batu dasar (bedrock). Sedangkan menurut Bowles (1984), tanah adalah campuran partikel-partikel yang terdiri dari salah satu atau seluruh jenis seperti berangkal (potongan batuan besar), kerikil, pasir, lanau, lempung, dan koloid. Peranan tanah ini sangat penting dalam perencanaan atau pelaksanaan bangunan karena tanah tersebut berfungsi untuk mendukung beban yang ada diatasnya, oleh karena itu tanah yang akan dipergunakan untuk mendukung konstruksi harus dipersiapkan terlebih dahulu sebelum dipergunakan sebagai tanah dasar (subgrade).

Faktor-faktor yang mempengaruhi hasil dari suatu proses pemadatan antara lain; besarnya energi pemadatan, kandungan air dalam tanah, dan jenis tanah.

1. Tujuan pemadatan adalah; Menaikkan berat volume, Meningkatkan kekuatan geser tanah, Meningkatkan kekakuan tanah

2. Manfaat pemadatan tanah:Memperbaiki kuat geser tanah yaitu menaikkan nila $\Theta$ dan $C$ (memperkuat tanah), Mengurangi kompresibilitas yaitu mengurangi penurunan oleh beban, Mengurangi permebelitas yaitu mengurangi nilai $\mathrm{K}$, Mengurangi sifat kembang susut tananh (lempung).

3. Pemadatan berfungsi untuk;

1. Meningkatkan kekuatan tanah, sehingga dengan demikian meningkatkan daya dukung pondasi diatasnya.

2. Mengurangi besarnya penurunan tanah yang tidak diinginkan

3. Meningkatkan kemampatan lereng timbunan

\section{METODE PENELITIAN}

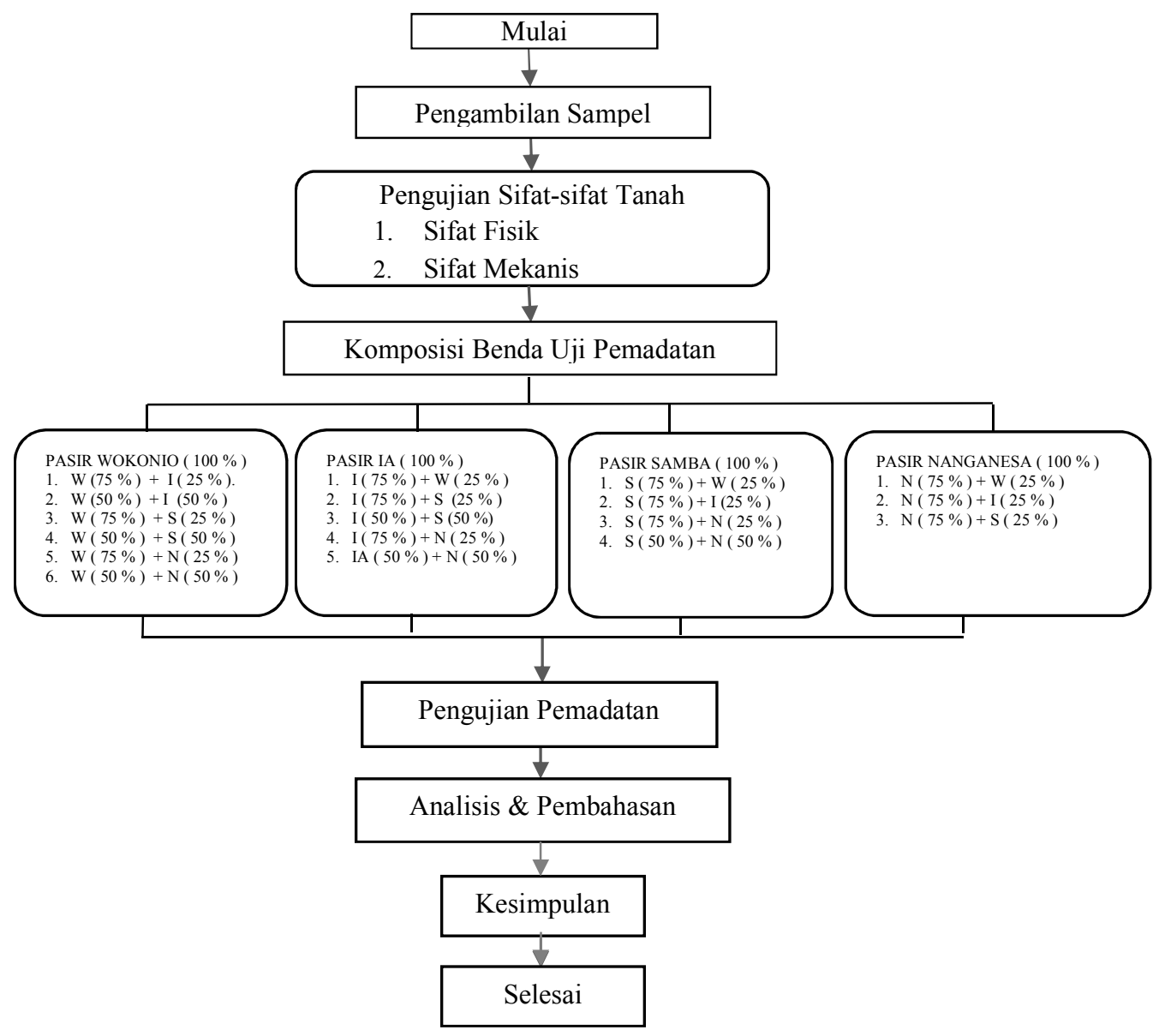

Gambar 1. Digram Alir Penelitian 


\section{HASIL DAN PEMBAHASAN}

pengujian yang telah dilakukan di Laboratorium Mekanika Tanah Fakultas Teknik Universitas Flores. Sampel tanah yang digunakan dalam penelitian ini adalah tanah yang diambil dari 4 quari, yaitu ; quari Ia, quari Samba, quari Nanganesa dan quari Wokonio

\section{Pengujian Fisik Tanah}

\begin{tabular}{ccccc}
\hline Jenis & Pasir Ia & Pasir Samba & Pasir Nanganesa & Pasir Wokonio \\
\hline Kerikil & 4,29 & 2,63 & 2,32 & 7,17 \\
Pasir & 63,38 & 54,96 & 42,38 & 50,16 \\
Lanau & 24,93 & 35,15 & 50,00 & 32,18 \\
Lempung & 7,41 & 7,26 & 5,30 & 10,51 \\
LL & 18,00 & 22,90 & 20,2 & 26,00 \\
PL & 17,00 & 20,00 & 0,00 & 21,00 \\
IP & 1,00 & 2,90 & 20,2 & 5,00 \\
AASTHO & Kelompok & Kelompok & Kelompok & Kelompok \\
& A -2 - 5 & A - 2 -5 & A - 1b & A - 2 - 5 \\
USCS & Pasir Halus & Pasir Halus & Lempung Berkerikil/ & Pasir Halus \\
& Berlanau & Berlanau & Berpasir & Berlanau \\
\hline
\end{tabular}

\section{Pemadatan Tanah Asli}

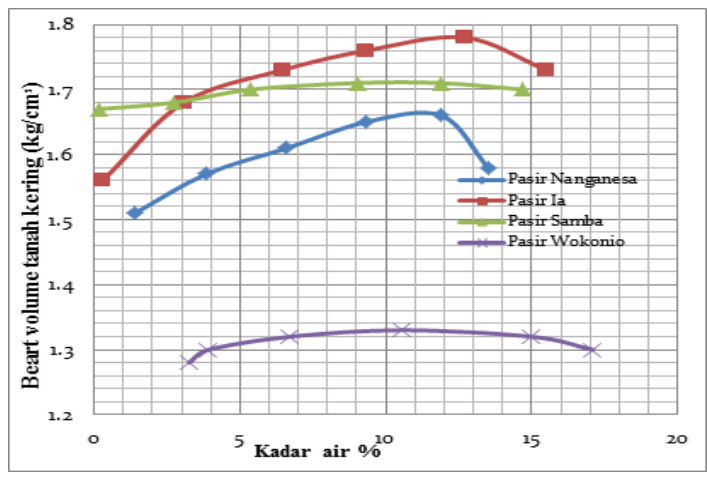

Gambar 2. Kurva Uji Kepadatan Tanah Asli

Berdasarkan gambar 2 menunjukkan bahwa dari ke empat Quari tersebut pasir yang mengalami pemadatan maksimal ialah pasir ia dengan berat volume tanah kering $1,78 \mathrm{~kg} / \mathrm{cm}^{3}$

\section{Pemadatan Tanah Campuran}

1. Campuran pasir Wokonio dengan pasir Samba, pasir Ia, dan pasir Nanganesa.

Tabel 1. Rencana Komposisi Campuran

\begin{tabular}{ccl}
\hline No & $\begin{array}{c}\text { Nama } \\
\text { Campuran }\end{array}$ & \multicolumn{1}{c}{ Komposisi Campuran } \\
\hline 1 & $\mathrm{~W}_{0}$ & Pasir Wokonio $(100 \%)$ \\
2 & $\mathrm{~W}_{1}$ & Pasir Wokonio $(75 \%)+$ Pasir Ia $(25 \%)$. \\
3 & $\mathrm{~W}_{2}$ & Pasir Wokonio $(50 \%)+$ Pasir Ia $(50 \%)$ \\
4 & $\mathrm{~W}_{3}$ & Pasir Wokonio $(75 \%)+$ Pasir Samba $(25 \%)$ \\
5 & $\mathrm{~W}_{4}$ & Pasir Wokonio $(50 \%)+$ Pasir Samba $(50 \%)$ \\
5 & $\mathrm{~W}_{5}$ & Pasir Wokonio $(75 \%)+$ Pasir Nanganesa $(25 \%)$ \\
6 & $\mathrm{~W}_{6}$ & Pasir Wokonio $(50 \%)+$ Pasir Nanganesa $(50 \%)$ \\
\hline
\end{tabular}




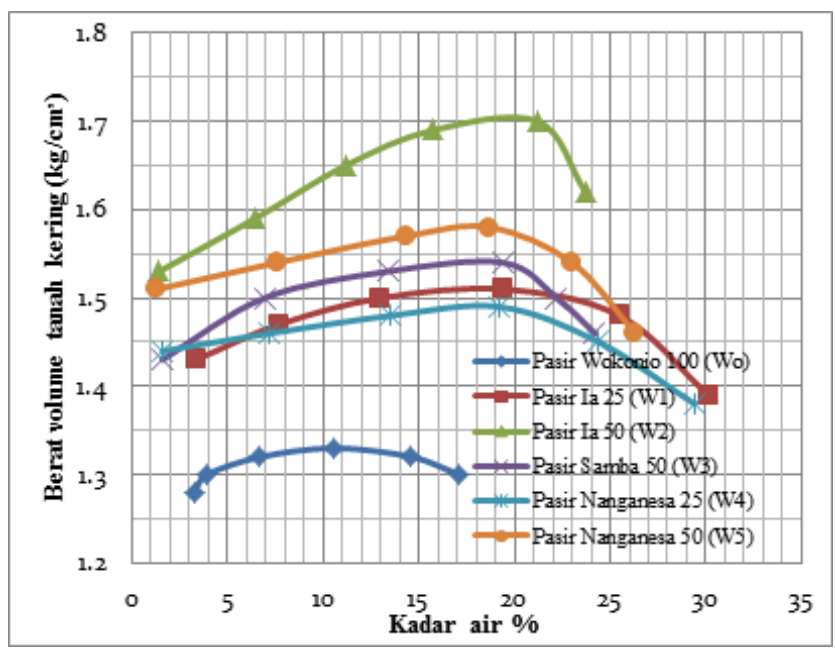

Gambar 3. Kurva Uji Kepadatan Kombinasi Pasir Wokonio, Ia, Samba dan Nanganesa.

2. Campuran pasir Ia dengan pasir Samba, pasir Nanganesa dan pasir Wokonio

Tabel 2. Rencana Komposisi Campuran

\begin{tabular}{ccl}
\hline No & Nama Campuran & \multicolumn{1}{c}{ Komposisi Campuran } \\
\hline 1 & $\mathrm{I}_{0}$ & Pasir Ia $(100 \%)$ \\
2 & $\mathrm{I}_{1}$ & Pasir Ia $(75 \%)+$ Pasir Wokonio $(25 \%)$ \\
3 & $\mathrm{I}_{2}$ & Pasir Ia $(75 \%)+$ Pasir Samba $(25 \%)$ \\
4 & $\mathrm{I}_{3}$ & Pasir Ia $(50 \%)+$ Pasir Samba $(50 \%)$ \\
5 & $\mathrm{I}_{4}$ & Pasir Ia $(75 \%)+$ Pasir Nanganesa $(25 \%)$ \\
6 & $\mathrm{I}_{5}$ & Pasir Ia $(50 \%)+$ Pasir Nanganesa $(50 \%)$ \\
\hline
\end{tabular}

Hasil pengujian pemadatan tanah campuran berdasarkan tabel diatas disajikan pada gambar 4. berikut ini. Sedangkan hasil percobaan selengkapnya dapat dilihat pada lampiran.

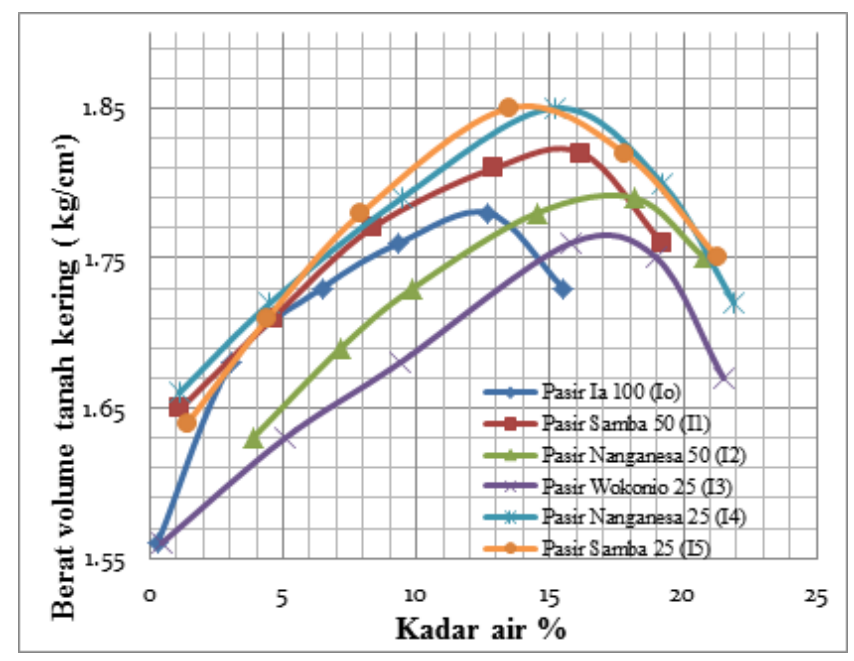

\section{Gambar 4. Kurva Uji Kepadatan Kombinasi Pasir Ia dengan Pasir Samba, Nanganesa dan Wokonio}

3. Campuran pasir Samba dengan pasir Ia, pasir Nanganesa dan pasr Wokonio.

Adapun komposisi campuran yang direncanakan dalam pengujian ini, antara lain sebagai berikut; 
Tabel 3. Rencana Komposisi Campuran

\begin{tabular}{|c|c|c|}
\hline No & $\begin{array}{c}\text { Nama } \\
\text { Campuran }\end{array}$ & Komposisi campuran \\
\hline 1 & $\mathrm{~S}_{0}$ & Pasir Samba (100\%) \\
\hline 2 & $\mathrm{~S}_{1}$ & Pasir Samba ( 75\%) + Pasir Wokonio ( 25\%) \\
\hline 3 & $\mathrm{~S}_{2}$ & Pasir Samba ( 75\%) + Pasir Ia (25\%) \\
\hline 4 & $\mathrm{~S}_{3}$ & Pasir Samba ( 75\%) + Pasir Nanganesa ( 25\%) \\
\hline 5 & $\mathrm{~S}_{4}$ & Pasir Samba ( 50\% ) + Pasir Nanganesa ( 50\% ) \\
\hline
\end{tabular}

Hasil pengujian pemadatan tanah campuran berdasarkan tabel diatas disajikan pada gambar 5 berikut ini.

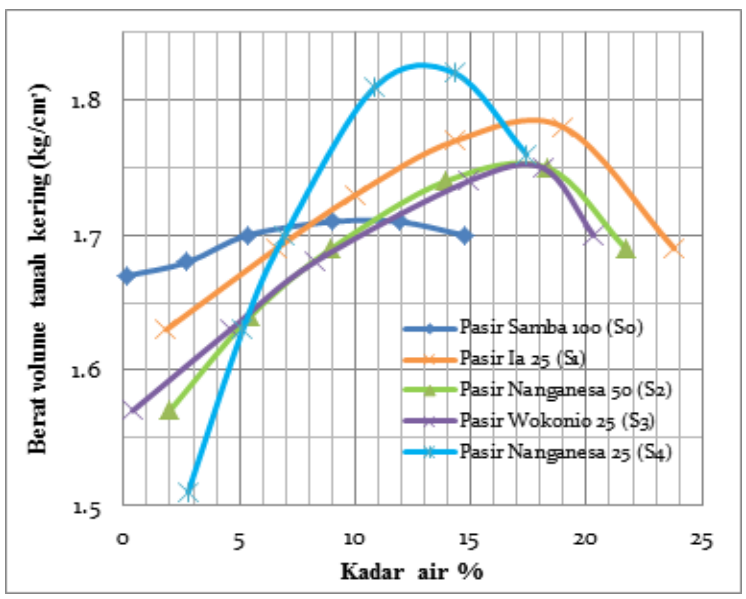

\section{Gambar 5. Kurva Uji Kepadatan Kombinasi Pasir Samba dengan Pasir Ia, Wokonio dan Nanganesa}

4. Campuran pasir Nanganesa dengan pasir Wokonio, pasir Ia dan pasir Samba

Adapun komposisi campuran yang direncanakan dalam pengujian ini, antara lain sebagai berikut;

Tabel 4. Rencana Komposisi Campuran

\begin{tabular}{ccl}
\hline No & Nama Campuran & \multicolumn{1}{c}{ Komposisi Campuran } \\
\hline 1 & $\mathrm{~N}_{0}$ & Pasir Nanganesa $(100 \%)$ \\
2 & $\mathrm{~N}_{1}$ & Pasir Nanganesa $(75 \%)+$ Pasir Wokonio ( $25 \%)$ \\
3 & $\mathrm{~N}_{2}$ & Pasir Nanganesa $(75 \%)+$ Pasir Ia $(25 \%)$ \\
4 & $\mathrm{~N}_{3}$ & Pasir Nanganesa $(75 \%)+$ Pasir Samba $(25 \%)$ \\
\hline
\end{tabular}

Hasil pengujian pemadatan tanah campuran berdasarkan tabel diatas disajikan pada gambar 6 berikut ini.

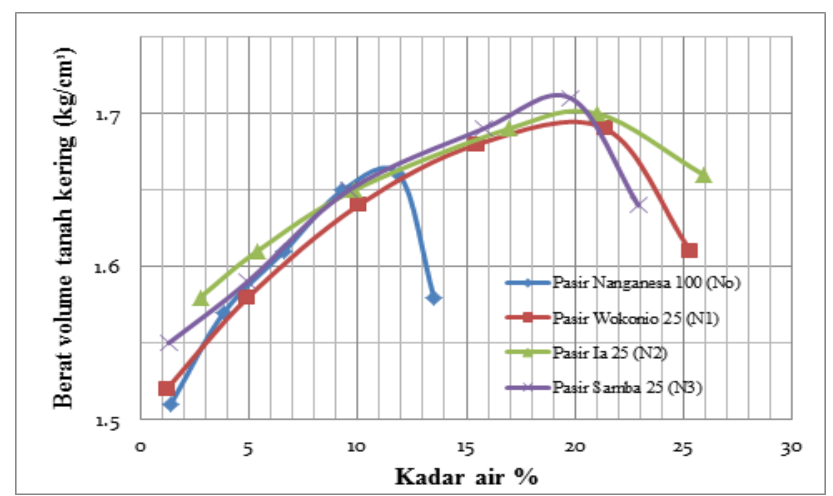

Gambar 6. Kurva Uji Kepadatan Kombinasi Pasir Nanganesa dengan Pasir Wokonio, Ia dan Samba 
Berdasarkan hasil dari pengujian pemadatan tanah di atas baik pemadatan pada kondisi tanah asli maupun pemadatan campuran dapat disimpulkan beberapa hal sebagai berikut :

a. Pemadatan tanah dilihat dari kondisi asli

Berdasarkan gambar 6 menunjukkan bahwa uji pemadatan dari ke empat quary pasir tersebut yang mencapai nilai kepadatan tertinggi dengan $\gamma_{\mathrm{d}}=1,78 \mathrm{~kg} / \mathrm{cm}^{3}$ ialah pasir Ia.

b. Pemadatan tanah dilihat dari perbandingan campuran antara lain :

1. Campuran pasir Wokonio dengan pasir Ia, Samba dan Nanganesa.

Berdasarkan gambar 3 menunjukkan bahwa hasil uji pemadatan dari campuran pasir Wokonio dengan pasir Ia, Samba dan Nanganesa terlihat bahwa nilai kepadatan tertinggi pada komposisi perbandingan pasir Wokonio $50 \%$ dengan pasir Ia $50 \%$ mendapatkan nilai $\gamma_{\mathrm{d}}=1,71 \mathrm{~kg} / \mathrm{cm}^{3}$.

2. Pasir Ia dengan pasir Wokonio, Samba dan Nanganesa

Berdasarkan gambar 4 menunjukkan bahwa hasil uji pemadatan pasir Ia dan pasir lain terlihat bahwa nilai kepadatan tertinggi diperoleh pada komposisi campuran pasir Ia $75 \%$ dan pasir Samba $25 \%$ serta pasir Ia $75 \%$ dan pasir Nanganesa $25 \%$ mendapatkan nilai $\gamma_{\mathrm{d}}=1,85 \mathrm{~kg} / \mathrm{cm}^{3}$.

3. Pasir Samba dengan pasir Ia, Nanganesa dan Wokonio

Berdasarkan gambar 5 menunjukkan bahwa hasil uji pemadatan dari pasir Samba dan pasir lain terlihat bahwa nilai kepadatan tertinggi pada komposisi perbandingan pasir Samba $75 \%$ dan pasir Nanganesa $25 \%$ mendapatkan nilai $\gamma_{\mathrm{d}}=1,83 \mathrm{~kg} / \mathrm{cm}^{3}$.

4. Pasir Nanganesa dengan pasir Wokonio, Ia dan Samba.

Berdasarkan gambar 6 menunjukkan bahwa hasil uji pemadatan dari pasir Nanganesa dan pasir lain terlihat bahwa nilai kepadatan tertinggi pada komposisi perbandingan pasir Nanganesa 75 $\%$ dan pasir Samba $25 \%$ mendapatkan nilai $\gamma_{\mathrm{d}}=1,73 \mathrm{~kg} / \mathrm{cm}^{3}$.

\section{KESIMPULAN}

Berdasarkan hasil penelitian dan analisa data, dapat disimpulkan beberapa hal sebagai berikut:

1. Tanah pasir dari empat quary menurut sistem klasifikasi AASHTO, termasuk dalam kelompok A1a dan A-3, dengan jenis-jenis bahan pendukung utama pasir halus. Tingkat umum sebagai tanah dasar adalah baik sekali. sedangkan menurut sistem klasifikasi tanah menurut USCS, termasuk dalam kelompok SW (pasir kerikil dan bergeradasi baik tanpa atau dengan sedikit bahan halus).

2. Dilihat dari hasil pengujian pemadatan tanah kondisi asli tersebut menunjukkan bahwa pasir dari ke empat quary tersebut yang mengalami nilai kepadatan tertinggi ialah pasir Ia dengan nilai berat volume tanah kering $1,788 \mathrm{~kg} / \mathrm{cm}^{3}$

3. Dilihat dari hasil pengujian pemadatan tanah dengan komposisi campuran tersebut menunjukan bahwa penggabungan yang mengalami pemadatan maksimal ialah pasir Ia yang di gabungkan dengan pasir samba dan pasir nanganesa dengan komposisi campuran pasir Ia $75 \%$ dan pasir Samba $25 \%$ serta pasir Ia $75 \%$ dan pasir Nanganesa $25 \%$ mendapatkan nilai $\gamma_{d}=1,85 \mathrm{~kg} / \mathrm{cm}^{3}$.

\section{DAFTAR PUSTAKA}

Bowles, JE. 1989. Mekanika Tanah (Sifat-sifat Fisik Dan Geoteknik Tanah) Jakarta : Edisi Kedua. Erlangga.

Das, BM. 1988. Mekanika Tanah (Prinsip-Prinsip Rekayasa Geoteknis). Jakarta : Jilid I. Erlangga.

Das, BM. 1988. Mekanika Tanah (Prinsip-Prinsip Rekayasa Geoteknis). Jakarta : Jilid II. Erlangga.

Giroud, JP. and Noiray L. 1981. Journal of Geotechnical Engineering. ASCE.

Hardiyatmo, HC. 2002. Mekanika Tanah. Yogyakarta : Universitas Gajah mada.

John S. 1987. Permasalahan tanah dalam pembangunan. Jakarta : Jilid II. Sinar Grafika.

Shirley, LH. 1992. Geoteknik dan Mekanika Tanah (Penyelidikan Lapangan dan Laboratorium).

Bandung : Penerbit Nova.

Sunggono, KH. 1984. Mekanika Tanah. Bandung : Penerbit Nova.

Terzhagi, K and Peck, RB. 1987. Mekanika Tanah Dalam Praktek Rekayasa. Jakarta : Jilid I. Erlangga.

Wesley, LD. 1977. Mekanika Tanah. Jakarta : Badan Penerbit Pekerjaan Umum. 